\title{
A new approach to solid waste landfills aerial monitoring
}

\author{
M. Lega \& R. M. A. Napoli \\ Dipartimento di Scienze per l'Ambiente, \\ University of Naples Parthenope, Italy
}

\begin{abstract}
The Solid Waste Landfilling (SWL) holds a high risk of fire emergencies and represents hazards to people and to the environment mainly due to sub-products, odors and volatile and non-volatile compounds.

In this paper we introduce a new integrated system based on a sensors array carried by an Unmanned Aerial Vehicles - Lighter Than Air (UAV-LTA; e.g. electric powered mini-blimp or tethered balloons).

The sensors array permits to detect: thermal emissions (dedicated to prevent fire upfront and to localize ignition points), chemical and physical parameters ( $\mathrm{CO}, \mathrm{NOx}, \mathrm{O} 3, \mathrm{CH} 4$, air temperature, relative humidity, etc.).

Moreover, the availability of viewpoints at different altitudes allow to enlarge the monitored area with full geometrical resolution using only one camera.

The project will be introduced in detail following the "iter" that starts from the main objectives and follows the close examination of additional criteria; thereafter it introduces the system specification proposed as natural satisfaction of the presuppositions; finally it ends with the experience gained "on the field" to support the effectiveness of developed system.

Currently we are upgrading the system with a new "payload" based on customized "bio-sensor" devices, able to detect specific aromatic compounds in the atmosphere.
\end{abstract}

Keywords: landfills monitoring, landfills fires, UAV LTA, termography.

\section{Introduction}

During last years, all over the industrialized countries the SWL became very unpopular due to the well-known environmental problems attributed to this practice. 
In Europe all the "minds energies" are focused to minimize and recycle SW to avoid or reduce the landfilling; but it isn't possible to assume, in the next tenths of years, a future without landfills since the others SW disposal methods haven't the same effectiveness and efficiency.

Surely the problems in SWL exist and the hazard to the people and to the environment is high; but what are the main problems of landfills? In just one word: production of undesiderable and/or toxic compounds that flow directly or through multiple patterns

- in the atmosphere: landfill gas (from soon after opening and for several hundred years thereafter), dust, odors, bio-aerosols, noise (predominantly from landfill site operation);

- in the water: leachate and contaminated surface water run-off, flowing directly to watercourses (ditches, streams, rivers etc) and into groundwater through permeable strata.

Surely a proper SW management would have to reduce the potential risk for the environment but, often, what is "potential" will becomes "real" in few seconds at the first unexpected event. Therefore the monitoring activities have to be strongly considered in all phases of the SW management because a simple anomaly could turn into a disaster.

In this paper we illustrate how to prevent fire upfront and to localize ignition points in the landfills using a UAV LTA platform with a specialized sensors array.

\section{Landfills fires}

A landfill fire occurs when the landfilled SW ignites and spreads. When the landfilled SW are not daily covered the increase of temperature due to biological decomposition can promote the spontaneous ignition of the waste. It is important to underline that often the landfill fires are also attributed to arson.

\section{Landfills monitoring}

Today the monitoring of air, surface water and groundwater is one of the main objective of the SWL management; this activity has become a major component of a facility operating budget.

The existing regulations on this topic are intended to help:

- to identify the environmental impact;

- to detect the source, the magnitude and the extent of a release;

- to assess the effectiveness of on-going cleanup activities.

Landfill air principal emissions are explosive gases, toxic or hazardous emissions and odorous or nuisance emissions. Nitrogen, carbon dioxide, methane and other organic constituents are monitored quarterly.

The exiting regulations issue limits for the concentrations and the monitoring frequencies for potentially explosive or toxic gases within the landfills boundary and for off-site structures potentially affected by migration of those gases. These above mentioned gases could collect at the landfill bottom and gain the explosive or toxic concentrations levels. 
Actual regulations list the maximum methane concentration of the lower explosive limit (LEL) at the property boundary and require:

- the monitoring of methane at the property boundary must have with a frequency at least quarterly;

- the maximum methane concentration has not to exceed the 25 percent of (LEL).

Thereafter the monitoring program must be suitable to the site-specific conditions that control gas generation and migration. Landfills with a low efficiency gas extraction system may require more frequent monitoring due to gas accumulation within the fill. Also, if native materials that contact the waste are very porous, the gas migration potential might call for frequent monitoring.

Establishing comprehensive sampling locations within structures is critical. Sampling stations must reflect areas of high gas migration and collection potential, as well as high explosive potential. Ignition sources or areas with open flames must also be included.

\subsection{Standard landfills monitoring instruments}

Today many technologies are available for the landfills monitoring and all main instruments companies have a section of the catalogue dedicated to this field.

It's impossible to describe all the existing instruments but the main categories are:

- Landfill gas monitor: usually, it is a portable field instrument to monitor main gases $\left(\mathrm{CH}_{4} \& \mathrm{CO}_{2}\right.$ by infrared absorption and $\mathrm{O}_{2}, \mathrm{H}_{2} \mathrm{~S}$ and $\left.\mathrm{CO}\right)$;

- Vapour sampling cap: it is placed where vapour or water monitoring is required. It permit to extract and to monitor vapour or water through the cap, without removing the cap from the well;

- Leachate deep-meter: liquid level indicator specifically designed to combat aggressive foam that could be present in the wells;

- Landfill gas (LFG) control wellheads can help prevent LFG migration and emissions, and subsurface fire;

- "In-situ” systems: dedicated to water level measurement, data logging, temperature reading etc.

The landfills monitoring systems also include a Groundwater sampling system that utilizes low flow pumping and some tools to permit the collection and removal of landfill condensate.

\section{The proposed monitoring system}

According to the aeronautical technical idiom, the illustration of the proposed monitoring system is splitted in two parts: the aerial platform and the payload

\section{The aerial platform}

The platform specifications derive as natural satisfaction of the missions' requirements: a safe, small size, aerial platform without people onboard.

The specific Lighter Than Air Unmanned Aerial Vehicle (UAV LTA) permits to grab the data at different altitude without to add pollutants produced by carrier 
engine and the perturbation due to "mixed flux" of the propellers or other aerodynamics lift systems. Moreover, the particular platform specification permits to minimize the hazard to people during the flight path.

The optimal final configuration is double: a mini-blimp electric powered to examine wide-areas in short-time missions or a tethered balloon for small-areas in long time missions.
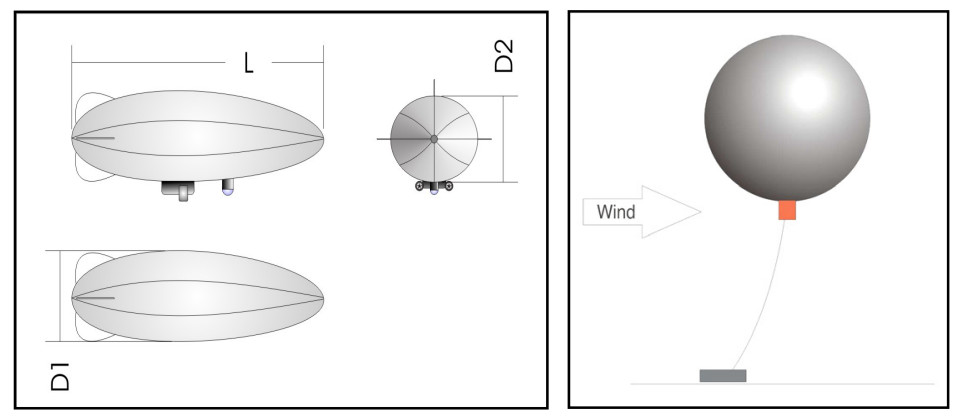

Figure 1: $\quad$ Mini UAV LTA configuration and Instrumented Tethered Balloon.

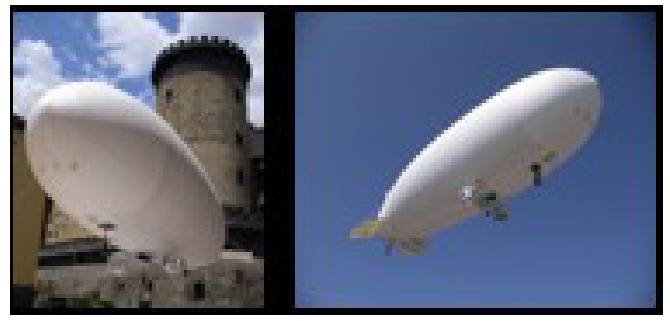

Figure 2: $\quad$ UAV LTA used in our tests during the flight in Campania - Italy.

\section{Payload}

Two are the items of he payload: an infrared camera, an array of sensors for detecting air parameters and service equipment.

An infrared camera detects radiation in the infrared range of the electromagnetic spectrum and produces images of that radiation. According to the black body radiation law, all objects emit the infrared radiation with intensity related to their temperatures. The amount of radiation emitted by an object increases with temperature; therefore, the thermography allows to see the environment as variations in temperature of the target objects. When viewed by infrared cameras, warm objects stand out well against cooler backgrounds.

In the proposed system we use an infrared camera carried onboard the UAV LTA and, therefore, the availability of view point at different altitudes allow to monitor a wide area with full geometrical resolution using only a single camera. The follows figures permit to understand the difference between a camera positioned on the ground and on an aerial vehicle, and moreover the fires over/under the ground surface. 


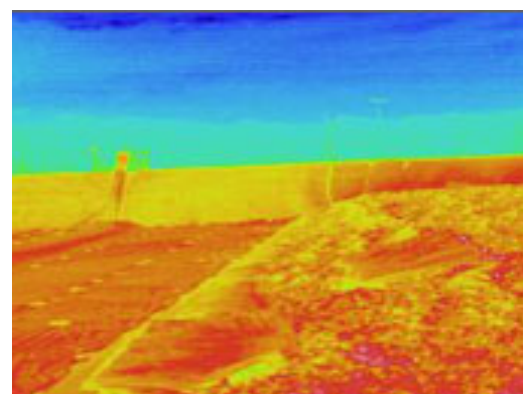

Figure 3: Landfills infrared ground-view (by FLIR Systems).
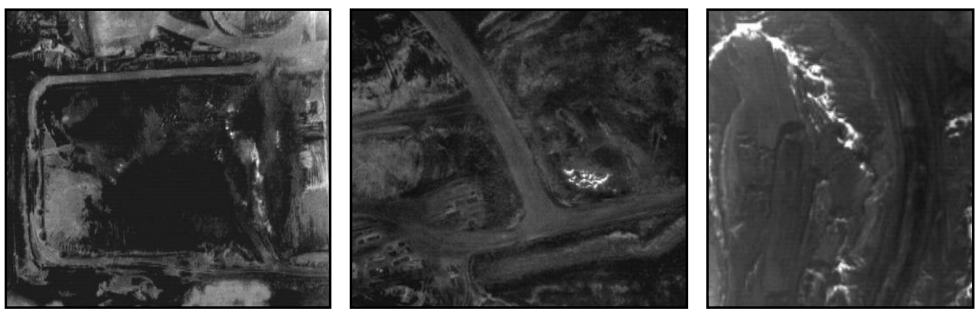

Figure 4: Landfills infrared aerial-views (by Gregory R. Stockton "Applications for Aerial Infrared Thermography").

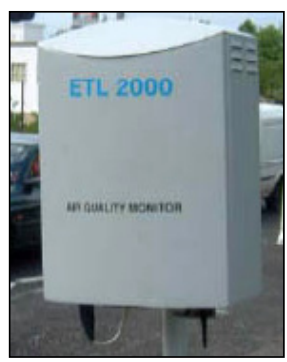

Figure 5: "Thick-film” sensors device.

Sensors array

This second item of the payload includes a multi-component air quality monitor device based on "thick film" sensors The measured parameters are: $\mathrm{CO}$, $\mathrm{NO}_{\mathrm{x}}, \mathrm{O}_{3}, \mathrm{CH}_{4}$, air temperature and relative humidity.

"Thick-film" sensors technology exploits electric conduction phenomena that happen above the layer of nano-structured semi-conducting metal oxides at the fixed temperature $\left(200-400^{\circ} \mathrm{C}\right)$. An electrical response from semiconductor is proportional to particular gas concentration. The signal is turned into given gas concentration using a suitable fitting calibration curve. 
We use ETL2000-BUS device, manufactured by UNITEC, but customized by our laboratories (light case, 12Volt power management system, forced flux, etc.) to permit the installation on our aerial platform.

Service equipment

The payload also includes: GPS, Data Logger, GSM modem and/or Wi-Fi network for remote data link/handling. A miniaturized device dedicated to Particulate Mass measurement (PM10, PM5, PM2,5), based on a piezo-crystal inertial micro-balance, is actually under-testing.

\section{Conclusions}

According to an environmental saving approach, any SW management must consider that:

- the used-up landfills must be monitored during the filling and, at least, as long as 20 years after the filling is completed;

- the monitoring activities must be extended to the waste dumps, hopefully increasing the efficiency;

- only few countries have the possibility to adopt the zero waste approach;

so it isn't possible to assume, in a short term, a future without landfills.

On this scene the proposed system could be a valid solution for the monitoring activities for the following reasons:

- it permits a macro area "status-view" with a single "shot";

- it permits to detect "invisibles anomalies" both in a short time and long time;

- it permits an integrated monitoring approach: to prevent - to manage - to alarm;

- it permits the landfill monitoring with low impact on the activities in progress;

- it detects different pollutants and emissions in/by various matrix (ground, air, water);

- it permits to discovery easily the pollution model: source-3D path- target.

The operating capabilities of the proposed system could be very useful also to fight Waste Dumps (WD) ad illegal discharges.

About WD the UAV-LTA platform, coupled with a specific payload as introduced in this paper, could win the obstacle of the ground detection of the WD, often hindered with thick covers (land, green, etc.); in fact this goal could be achieved just using as target an heat source such like the bacterial activities phenomena, always existing in solid waste landfills.

Moreover, the aerial monitoring could be use in the WD reclamation activity to detect the landfills fires, which is the main problem together with uncontrolled leachate for such kind of environmental polluter.

Finally, the proposed system could be use to detect a wide range of legal/illegal environmental pollution sources e.g.: 
- to detect illegal dumping/discharge in the water;

- to track pollution such as waste spills or oil spills;

- to monitor effluents from storm drains and sewage treatment plant;

- to monitor ground water seepage into rivers, streams, lakes and estuary;

- to manage heated water from power plant cooling towers.

\section{Acknowledgements}

We thank UNITEC s.r.l. and SFERA s.c.a.r.l. (University Parthenope spin-off) for the contribution to the researches activities.

Special thanks to Luca D'Antonio for the contribute to the conclusions of this paper.

\section{References}

[1] M. Lega, R.M.A. Napoli - "New guidelines for Environmental Monitoring and advanced technologies for 3D field data acquisition", Convegno Nazionale di Fisica della Terra Fluida e Problematiche Affini, Ischia 11-15 june 2007

[2] M. Lega - "Monitoraggio e Studi Ambientali con l'utilizzo di UAV - LTA" Workshop PRIN, Taormina 2006

[3] M. Lega, S. Dumontet, R.M.A. Napoli - "Mini-Dirigibile UAV per missioni di Monitoraggio, Sicurezza e Studi Ambientali", Poster tecnico: "Ricerca e tecnologia per la sicurezza: la collaborazione tra Finmeccanica e il sistema universitario", Rome, 10 nov 2005

[4] M. Lega, M. Guida, R.M.A. Napoli, A. Salerno, F. Aliberti - "Le nuove metodologie di campionamento nella valutazione dell'inquinamento aerodisperso", Rivista: Biologi Italiani, $\mathrm{n}^{\circ} 9$ oct 2005

[5] M. Lega, F. Aliberti, R.M.A. Napoli - "Nuove strategie di Monitoraggio Ambientale", XVIII Congresso Internazionale: "Sicurezza alimentare, rischio biologico e chimico, certificazione integrata, biomonitoraggio ambientale", 'European Countries Biologists Association, Bellaria (Rimini), 29 settembre $-1^{\circ}$ oct 2005

[6] M. Lega, M. Mansi, R.M.A. Napoli - "Monitoraggio dell'inquinamento dell'aria: nuove frontiere", $26^{\circ}$ Corso di Aggiornamento in tecniche per la difesa dall'inquinamento, Guardia Piemontese (CS), 22-25 june 2005

[7] H. Pyta, M. Pawłowski - "Application of semiconductive chemical sensors to control the concentration of benzene in the air"

[8] Gregory R. Stockton - "Applications for Aerial Infrared Thermography" 